\title{
Expression of the Membrane-Associated Resistance Protein RPW8 Enhances Basal Defense Against Biotrophic Pathogens
}

\author{
Wenming Wang, ${ }^{1}$ Alessandra Devoto, ${ }^{2}$ John G. Turner, ${ }^{2}$ and Shunyuan Xiao ${ }^{1}$ \\ ${ }^{1}$ Center for Biosystems Research, University of Maryland Biotechnology Institute, Rockville 20850, U.S.A.; ${ }^{2}$ School \\ of Biological Sciences, University of East Anglia, U.K.
}

Submitted 28 December 2006. Accepted 21 March 2007.

\begin{abstract}
The powdery mildew resistance genes $R P W 8.1$ and $R P W 8.2$ from Arabidopsis differ from the other isolated plant resistance $(R)$ genes in their predicted protein domains and their resistance spectrum. The two homologous $R P W 8$ genes encode small proteins featuring a predicted amino-terminal transmembrane anchor domain and a coiled-coil domain and confer resistance to a broad spectrum of powdery mildews. Here, we show that Arabidopsis plants expressing the $R P W 8$ genes have enhanced resistance to another biotrophic pathogen, Hyaloperonospora parasitica, raising the possibility that the $R P W 8$ genes may function to enhance salicylic-acid-dependent basal defenses, rather than as powdery-mildew-specific $R$ genes. When overexpressed from their native promoters, the $R P W 8$ genes confer enhanced resistance to the Cauliflower mosaic virus, but render plants more susceptible to the necrotrophic fungal pathogens Alternaria and Botrytis spp. Furthermore, we show that the RPW8 proteins appear to be localized to the endomembrane system, overlapping with the endoplasmic reticulum-associated small GTPase SAR1, and accumulate to higher levels in response to application of exogenous salicylic acid, one of the signaling molecules of plant defense.
\end{abstract}

Plants have sophisticated defense systems to protect themselves from different types of pathogens. Based on the mode of parasitism, plant pathogens generally can be divided into i) biotrophs that require live host cells at all stages of infection for completing their life cycle, ii) hemibiotrophs that require live host cells at an early stage of infection for successful colonization, and iii) necrotrophs that appear to kill host cells and feed on them (Glazebrook 2005). Tremendous progress has been made toward understanding the molecular mechanisms of plant resistance against biotrophic and hemibiotrophic pathogens. In many cases, resistance is controlled by resistance (R) proteins featuring a nucleotide binding site (NBS) and leucinerich repeats (LRR) (Dangl and Jones 2001) and is associated with a hypersensitive response (HR), a rapid and localized cell death at the site of infection (Hammond-Kosack and Jones

Corresponding author: S. Xiao; E-mail: xiao@umbi.umd.edu; Fax: +1240-314-6255.

Current address of A. Devoto: School of Biological Science, Royal Holloway, University of London, Egham, Surrey, TW20 0EX, U.K.

* The $\boldsymbol{e}$-Xtra logo stands for "electronic extra" and indicates that Figures 1,2 , and 3 appear in color online. A supplemental figure is also available online.
1997; Heath 2000; Staskawicz et al. 1995). The NBS-LRR proteins are thought to directly or indirectly recognize pathogen effectors and activate local resistance at the site of infection and later systemic acquired resistance (SAR) in uninoculated parts of the plants through conserved signaling pathways that often engage the signaling molecule salicylic acid (SA) (Belkhadir et al. 2004; Durrant and Dong 2004; Glazebrook 2001). In contrast, relatively little is known about how plants detect the invasion of necrotrophic pathogens and initiate defense signaling. However, many reports have demonstrated that plant hormones jasmonic acid (JA) and ethylene (ET) orchestrate the host defense signaling in response to attack from necrotrophic pathogens, and that there is cross-talk between the SA-dependent and JA-ET-dependent defense signaling (Feys and Parker 2000; Glazebrook 2005; Gupta et al. 2000). Generally, it has been shown that strong activation of one pathway represses the other, suggesting there is an overall mutually antagonistic relationship between these two distinct pathways although, at low magnitudes or early stages of signaling activation, these two pathways may be synergistic (Mur et al. 2006).

Powdery mildew comprises an important group of biotrophic fungal pathogens that cause diseases on numerous plant species (Braun 1987; Whipps et al. 1998). The two homologous Arabidopsis $R$ genes, $R P W 8.1$ and $R P W 8.2$, confer broadspectrum resistance to multiple powdery mildew isolates that belong to distinct Erysiphe spp. (Xiao et al. 2001). In contrast, most characterized $R$ genes confer resistance to one or a few isolates of a particular pathogen carrying the corresponding avirulence (Avr) gene (Hammond-Kosack and Jones 1997). Both $R P W 8.1$ and $R P W 8.2$ (together hereafter referred to as $R P W 8$, unless otherwise indicated) encode small, basic proteins with a putative $\mathrm{N}$-terminal transmembrane domain and a coiledcoil (CC) domain (Xiao et al. 2001). Our earlier analyses showed that transcription of the $R P W 8$ genes is induced to higher levels by powdery mildew; $R P W 8$-overexpresssion from the native promoters results in spontaneous HR-like lesions (SHL) and induction of $P R$ genes (Xiao et al. 2003); and the $R P W 8$ genes appear to trigger $\mathrm{HR}$ and resistance via a pathway that engages signaling components SA, PAD4, EDS1, EDS5, and NPRI (Xiao et al. 2005) that also are recruited by $N B S$ $L R R$ genes containing a toll-interleukin receptor 1 (TIR)-encoding domain (Aarts et al. 1998; van der Biezen et al. 2002). Interestingly, these signaling components also are implicated in basal resistance against virulent biotrophic or hemibiotrophic pathogens (Wiermer et al. 2005; Xiao et al. 2005). A model has been proposed to explain $R P W 8$-mediated broad-spectrum resistance (Xiao et al. 2005). In this model, expression of $R P W 8$ could be directly or indirectly induced by invasion of 
powdery mildew isolates and amplified by an SA-feedback circuit, leading to activation of defense responses via a conserved basal resistance pathway in a non-race-specific manner. Based on this hypothesis, it is anticipated that the $R P W 8$ genes may condition resistance against other types of biotrophic pathogen if appropriately induced at pathogen invasion sites. In this analysis, we show that expression of $R P W 8$ confers enhanced resistance to the oomycete Hyaloperonospora parasitica, a biotrophic pathogen different from powdery mildew. This provides direct evidence for the above model. However, overactivation of the SA pathway by $R P W 8$ overexpression leads to enhanced susceptibility to necrotrophic pathogens (Alternaria and Botrytis spp.), conforming to the notion of a mutually antagonistic relationship between SA- and JA-ET-dependent defenses. We also show that the RPW8 proteins are associated mainly with the endomembrane system, overlapping with the small GTPase SAR1, and accumulate at higher levels upon exogenous SA application.

\section{RESULTS}

\section{$R P W 8$ expression leads}

to enhanced resistance to $H$. parasitica.

The $R P W 8$ locus contains two powdery mildew $R$ genes, and transgenic plants with Col-0 containing the glabrous mutation, $g l-1$ (Col-gl) expressing $R P W 8.1$ and $R P W 8.2$ from their native promoters did not show resistance to the oomycete pathogen, $H$. parasitica $(H p)$ isolate noco2 (Xiao et al. 2001). However, the disease test with $H$. parasitica noco 2 was done in $100 \%$ relative humidity $(\mathrm{RH})$ and subsequent studies indicated that transcription of $R P W 8.1$ and $R P W 8.2$ was attenuated under these conditions (Xiao et al. 2003).

Therefore, we used two approaches to reexamine whether the $R P W 8$ locus contributes to resistance against $H$. parasitica noco2. The first was based on our observation that, although $R P W 8$ transcription was attenuated at $100 \% \mathrm{RH}$, it was not completely suppressed (Xiao et al. 2003). We reasoned that there may be sufficient $R P W 8$ transcription in lines containing multiple copies of $R P W 8$ to compensate for the reduced transcription at this humidity. The three homozygous Col-gl lines, S5, S6, and S24, containing a single copy, two copies, and at least four copies, respectively, of $R P W 8$ under control of the native promoters (Xiao et al. 2003) were tested, along with Col-gl and Ms-0 (the natural accession from which the two $R P W 8$ genes were isolated) (Xiao et al. 2001), for resistance to $H$. parasitica noco2. Seedlings were grown on MurashigeSkoog (MS)-agar medium for 2 weeks and then were transferred into sterilized perlite in Magenta boxes to permit $R P W 8$ transcription. Three days after transfer, plants were sprayed with noco 2 and maintained inside perlite-containing magenta boxes $(\mathrm{RH}=100 \%)$. Ms-0 plants were completely resistant to noco 2 even under $\mathrm{RH}=100 \%$ conditions (not shown), suggesting that Ms-0 may contain a functional RPP5 (Parker et al. 1997 ) or similar $R$ allele that confers resistance to the pathogen. S5 was only slightly less susceptible than Col-gl to $H$. parasitica noco2 (Fig. 1A[a] and B), in agreement with our previous results (Xiao et al. 2001). However, S6 and S24 plants had apparent enhanced resistance to noco2, with $\approx 3 \times$
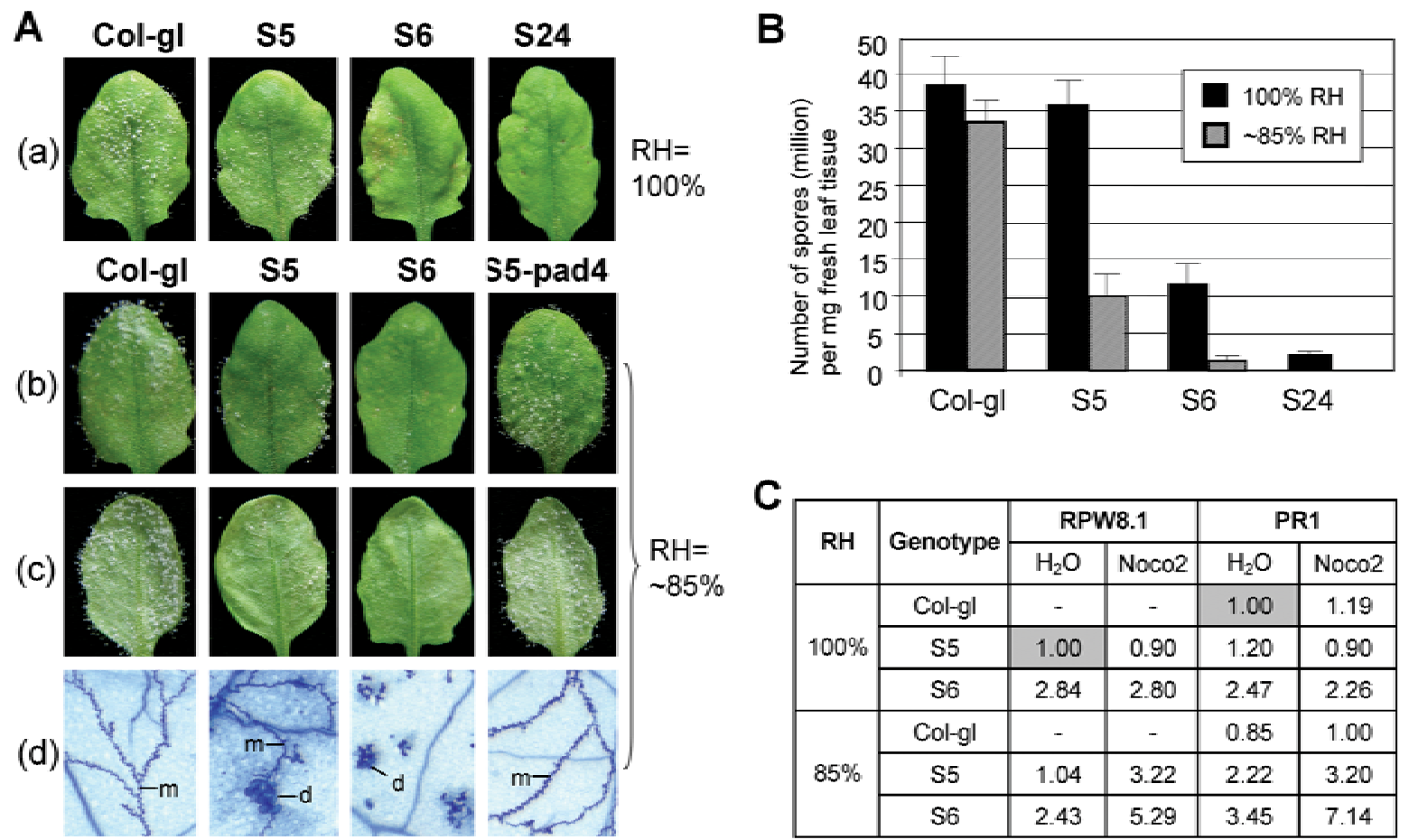

\begin{tabular}{|c|c|c|c|c|c|}
\hline \multirow{2}{*}{ RH } & \multirow{2}{*}{ Genotype } & \multicolumn{2}{|c|}{ RPW8.1 } & \multicolumn{2}{|c|}{ PR1 } \\
\cline { 3 - 6 } & & $\mathrm{H}_{2} \mathrm{O}$ & Noc02 & $\mathrm{H}_{2} \mathrm{O}$ & Noc02 \\
\hline \multirow{3}{*}{$100 \%$} & Col-gl & - & - & 1.00 & 1.19 \\
\cline { 2 - 6 } & $\mathrm{S} 5$ & 1.00 & 0.90 & 1.20 & 0.90 \\
\cline { 2 - 6 } & $\mathrm{S} 6$ & 2.84 & 2.80 & 2.47 & 2.26 \\
\hline \multirow{3}{*}{$85 \%$} & Col-gl & - & - & 0.85 & 1.00 \\
\cline { 2 - 6 } & $\mathrm{S} 5$ & 1.04 & 3.22 & 2.22 & 3.20 \\
\cline { 2 - 6 } & $\mathrm{S} 6$ & 2.43 & 5.29 & 3.45 & 7.14 \\
\hline
\end{tabular}

Fig. 1. RPW8 expression enhances basal resistance to Hyaloperonospora parasitica. A, Seedlings (18 for each genotype) of indicated genotypes were grown in MS-agar medium and soil for 2 weeks and transplanted into perlite in sealed Magenta boxes (a) and into soil in pots (b and c), respectively, under relative humidity $(\mathrm{RH})=100 \%$ (a) and $85 \%$ (b and c). Three days after transplanting, the seedlings were inoculated with $H$. parasitica noco 2 at a concentration of $\approx 5$ $\times 10^{4}$ spore $/ \mathrm{ml}$. Infection results were shown by representative leaves of each indicated genotype-treatment from the adaxial side (b) and abaxial side (c) at 6 days postinoculation (dpi). Induction of host cell death in inoculated leaves was revealed by trypan blue staining at $4 \mathrm{dpi}(\mathbf{d})$; $\mathrm{m}=$ fungal mycelium and $\mathrm{d}=$ dead cells. B, Twenty most susceptible leaves from 18 seedlings of each genotype in A (a and b) were pooled, weighed, and counted for the number of spores per milligram of fresh tissue. These experiments were repeated twice with similar results and data from one of the three experiments were shown in B. $\mathbf{C}$, Col-gl, S5, and S6 seedlings were prepared as in A(b) and infected with $H$. parasitica noco 2 under $\mathrm{RH}=100$ and $85 \%$ conditions. Infected leaves were subject to transcript analysis at 4 dpi for $R P W 8.1$ and $P R l$ by quantitative reverse-transcriptase polymerase chain reaction. The $R P W 8.1$ mRNA levels of all samples were compared with that in $\mathrm{S} 5$ under $\mathrm{RH}=100 \%(1.00)$ and the $P R 1 \mathrm{mRNA}$ levels were compared with that in Col-gl under RH = 100\% (1.00) using ACT2 as the endogenous control (Xiao et al. 2003). Shaded data were calibrators used for comparison among relevant samples. This experiment was repeated once with similar results. Data from one experiment was shown. 
and $\approx 19 \times$ reduction, respectively, in the number of conidia produced per milligram of infected leaf tissue compared with Col-gl plants (Fig. 1A and B). We measured the mRNA levels of $R P W 8.1$ and $P R I$ by quantitative reverse-transcriptase polymerase chain reaction (qRT-PCR) in Ms-0, S5, S6, and S24 seedlings under $100 \% \mathrm{RH}$ before inoculation. We found that the levels of mRNA for RPW8.1 in S5, S6, and S24 were 1.1, 2.0 , and 24.5 of that in Ms-0, respectively, and the levels of mRNA for PR1 in S5, S6, and S24 were $1.0 \times, 2.4 \times$, and $3.2 \times$ of that in Ms-0, respectively, which generally agrees with the results obtained with soil-grown seedlings (Xiao et al. 2003) (discussed below and Fig. 1C). These observations indicated that higher levels of RPW8 expression in S6 and S24 resulted in enhanced resistance to $H$. parasitica noco2.

The second approach was to keep the inoculated plants under the lowest possible $\mathrm{RH}$ that permitted infection by $H$. parasitica noco2, in the expectation that these conditions might minimize attenuation of $R P W 8$-expression. We found that noco 2 could not significantly infect Col-gl when RH was at or lower than $85 \%$. However, when inoculated plants were kept under $100 \% \mathrm{RH}$ for $24 \mathrm{~h}$ after inoculation and then maintained under $\approx 85 \%$ RH for 5 to 7 days, Col-gl plants showed infection on inoculated leaves, with fewer conidiophores on the adaxial side of the inoculated leaves (Fig. 1A[b]) and more formed in the abaxial side (Fig. 1A[c]). We then tested soilgrown S5, S6, and Col-gl plants with the pathogen under the above conditions (100\% RH for 1 day and $85 \%$ RH for 6 days). As expected, we found that S6 plants were nearly completely resistant to the pathogen. More significantly, S5 plants clearly had enhanced resistance to $H$. parasitica noco2, with an $\approx 3 \times$ reduction in number of conidia produced per milligram of infected leaf tissue compared with Col-gl under these conditions (Fig. 1B). In most cases, enhanced resistance in the Col-gl $R P W 8$ transgenic lines appeared to be associated with pathogeninduced cell death, with S6 having the stronger and more rapid cell death (Fig. 1A[d]). To further establish the correlation between $R P W 8$ expression and enhanced resistance against noco2, we measured mRNA levels of $R P W 8.1$ and $P R 1$ by qRT-PCR in inoculated leaves of soil-grown Col-gl, S5, and S6 seedlings at 4 days postinoculation (dpi). The RPW8.1 mRNA levels were 2 to $3 \times$ times higher in S6 than in S5 in both mock- and noco2-inoculated seedlings (Fig. 1C). This coincided with the slightly higher levels of $P R 1$ mRNA in both mock- and noco2-inoculated S6 in comparison with that of S5 (Fig. 1C) and higher level of resistance in S6 to the pathogen (Fig. 1A and B). Significantly, we found that, compared with mock inoculation, $R P W 8.1$ was induced by $\approx 3$ and $\approx 2 \times$ and $P R 1$ was induced by $\approx 1.5$ and $\approx 2 \times$ in S5 and S6, respectively, by $H$. parasitica noco 2 at $85 \%$ RH. However, there was no apparent induction of $R P W 8.1$ or $P R 1$ in $\mathrm{S} 5$ or $\mathrm{S} 6$ by noco 2 at $100 \%$ RH. To further confirm that it was the $R P W 8$ expression that rendered S5 with enhanced resistance to noco2, we tested plants containing the RWP8 transgene from S5 and the pad4-1 mutation under $\approx 85 \% \mathrm{RH}$ conditions and found that they were as susceptible as Col-gl (Fig. 1A[b and c]). pad4-1 has been shown to greatly attenuate $R P W 8$ expression and abolish $R P W 8$-mediated powdery mildew resistance (Xiao et al. 2005). Therefore, loss of enhanced resistance to noco2 in S5-pad4-1 plants probably was caused by insufficient expression of $R P W 8$.

Taken together, the above results indicate that $R P W 8$ expression enhances resistance to $H$. parasitica noco2, and suggest that $R P W 8$ may function in general defense rather than powdery-mildew-specific resistance.

\section{$R P W 8$ overexpression leads to enhanced resistance to Cauliflower mosaic virus.}

To see whether $R P W 8$-expressing plants have enhanced resistance to other types of pathogens, we inoculated Cauliflower mosaic virus (CaMV; Cabb B-JI strain) (Cecchini et al. 1998) on Col-gl, S5, and S24 plants immediately after transfer from nonpermissive (MS agar $+\mathrm{RH}=100 \%$ ) to permissive conditions (perlite $+\mathrm{RH}=85 \%)$. Both Col-0 and S5 ( $\approx 35$ plants tested for each genotype) were fully susceptible to CaMV. Infected Col-gl and S5 plants developed typical vein-clearing or banding and chlorosis with curled leaf and distorted rosette at 15 to 20 dpi (Fig. 2A[a]), and both were unable to initiate inflorescence (Cecchini et al. 1998). However, 23 of $33(\approx 70 \%)$
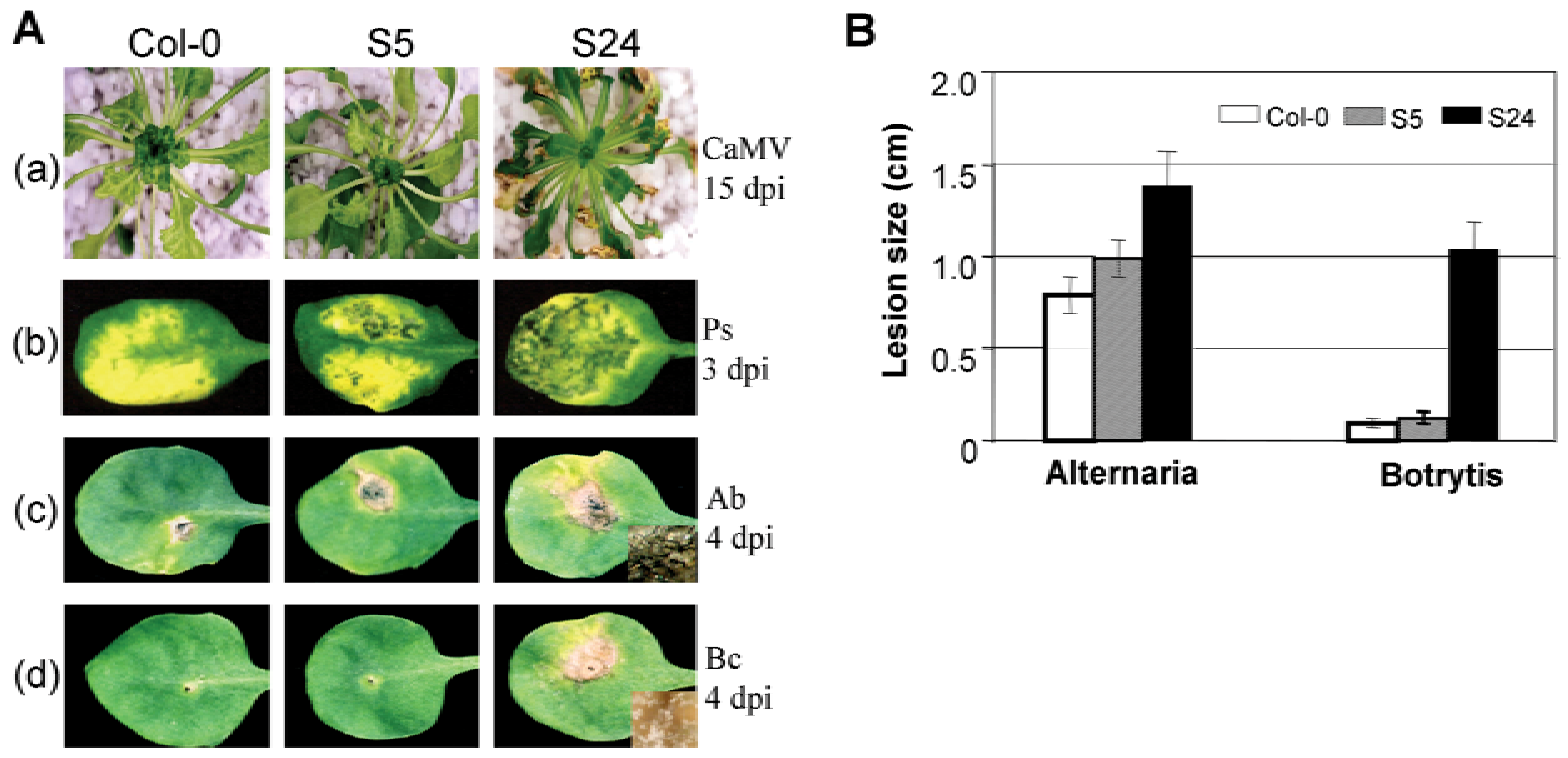

Fig. 2. $R P W 8$ overexpression results in altered responses to other pathogens. A (a through d), Five-week-old plants of the indicated genotypes grown in MSagar plates were inoculated with Cauliflower mosaic virus strain Cabb B-JI (CaMV), Pseudomonas syringae pv. maculicola ES4326 (Ps), Alternaria brassicicola MUCL $20297(\mathrm{Ab})$, and Botrytis cinerea IMI $169558(\mathrm{Bc})$ and transplanted to perlite. In all, 15 to 35 plants for each genotype were used in each treatment. A representative leaf photographed at the indicated times was shown for each genotype-pathogen treatment. $A b$ and $B c$ fungi observed in the infection sites were shown as small inset pictures. These tests were repeated twice with similar results. B, Lesions caused by $A b$ and $B c$ in A were measured at 4 days postinoculation (dpi). Data represented the mean \pm standard deviation from three independent experiments. 
S24 plants had no disease symptoms, exhibited SHL, and developed normal inflorescence as mock-inoculated plants (not shown); the remaining 10 plants developed some degree of vein banding and chlorosis, which were less severe compared with Col-0 and S5 plants (data not shown). These results indicated that expression of $R P W 8$ at a very high level could lead to enhanced resistance against $\mathrm{CaMV}$, which strictly requires live host cells to multiply.

\section{$R P W 8$ overexpression has no effect on resistance to Pseudomonas spp. but enhances susceptibility to Alternaria and Botrytis spp.}

Five-week-old, MS agar-grown Col-gl, S5, and S24 plants were inoculated with the virulent bacterial pathogen Pseudomonas syringae pv. maculicola ES4326 and immediately transferred to perlite under conditions of $\mathrm{RH}=$ approximately $85 \%$. Unexpectedly, we found no significant difference between Col-gl, S5, and S24 both in terms of disease symptoms (yellowing of inoculated leaves) and multiplication of bacteria (Fig. 2A[b]). However, there was an $\approx 2 \times$ increase in bacterial growth and more rapid necrosis of inoculated leaves in S24 compared with Col-gl and S5. These results suggested that $R P W 8$ overexpression triggered SHL and activation of defenserelated genes had no or slightly negative effect on defenses against $P$. syringae pv. maculicola.

Necrotrophic fungal pathogens have a mode of parasitism different from biotrophic pathogens (Glazebrook 2005). To analyze whether $R P W 8$ overexpression alters responses to this type of pathogens, we tested Alternaria and Botrytis spp., both of which are necrotrophic fungal pathogens that cause diseases in Arabidopsis (Glazebrook 2005). Preparation and growth conditions of plants were the same as in the test with $P$. syringae pv. maculicola. Infection tests with Alternaria brassicicola (strain MUCL2029) showed that S24 was significantly more susceptible than Col-gl and S5, as indicated by progression of the pathogen around the inoculated sites and the diameter of the cell death lesions caused by the pathogen (Fig. 2A[c] and B). The pathogen-induced lesions on S5 were slightly bigger than those in Col-gl. Similar results were obtained with Botrytis cinerea (strain IMI169558), except that no difference was observed between Co-gl and S5 (Fig. 2A[d] and B). Wounding and mock inoculation did not induce any cell death on these three genotypes within the time frame of the tests. These results suggested that $R P W 8$ overexpression did not activate defenses against these necrotrophic pathogens; instead, the pathogens might have actively taken advantage of potentiation of HR cell death by $R P W 8$ overexpression in $\mathrm{S} 24$ to maximize their propagation.

\section{$H A: R P W 8.2$ encodes a functional protein.}

The deduced RPW8.1 and RPW8.2 proteins contain an N-terminal transmembrane domain (RPW8.1, MPIGELAIGAVLG VGAQAIYDR; RPW8.2, MIAEVAAGGALGLALSVLHEAV; predicted by ConPred II and TMpred). For functional analysis of the RPW8 proteins, we made a construct to produce a translational fusion between a haemagglutinin (HA) intron-epitope tag (Ferrando et al., 2000) and RPW8.2 at the N terminus. The expression of the $H A-R P W 8.2$ fusion gene was controlled by the constitutive CaMV $35 S$ promoter or the $R P W 8.2$ native promoter $(\mathrm{Np})$ which is $1,000 \mathrm{bp}$ upstream of the start codon of RPW8.2 containing two W-boxes (Xiao et al. 2003). W-box (TTGACC/T) is a cis-acting element found in promoters of
A

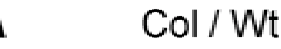

(a)

(b)
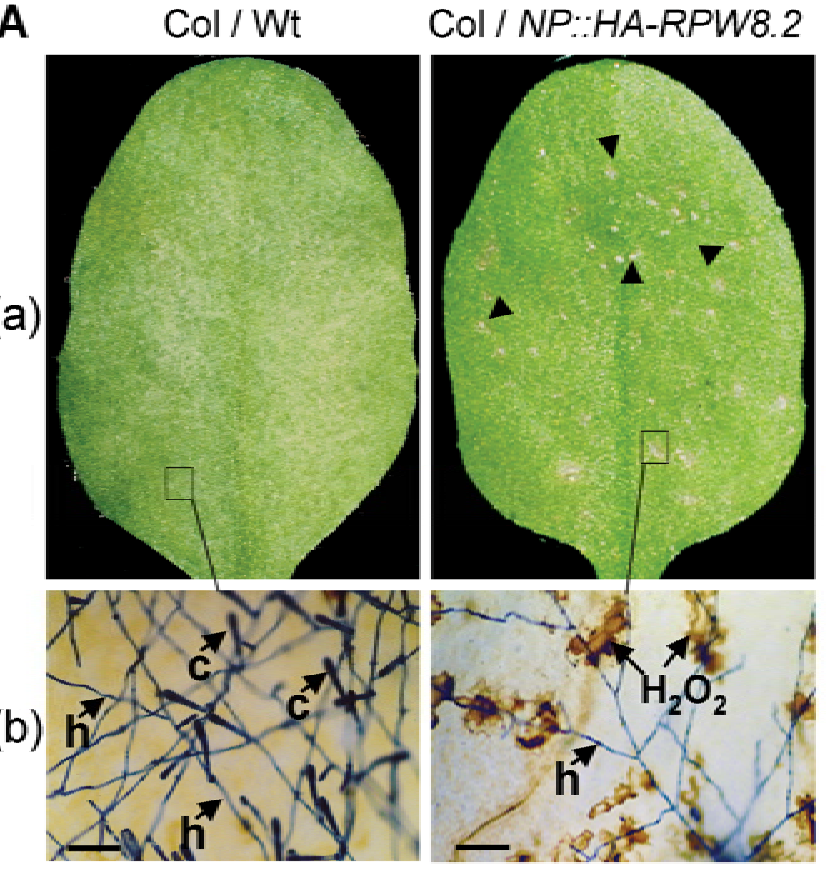

B

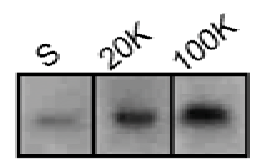

C

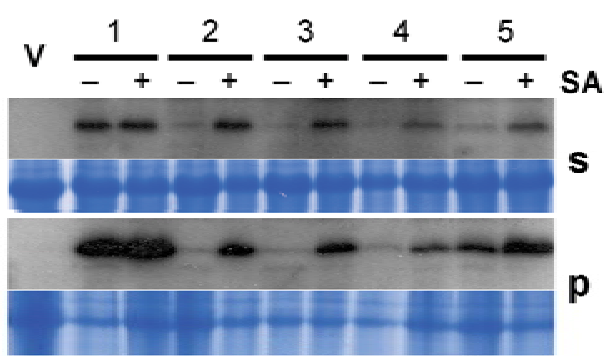

Fig. 3. HA:RPW8 is functional, enriched in membrane-enriched fractions, and induced by salicylic acid (SA). A, Four-week-old Col-gl wild-type and homozygous Col-gl transgenic plants expressing HA-RPW8.2 under control of the native promoter $(\mathrm{Np})$ were inoculated with Erysiphe cichoracearum UCSC1. Accumulation of $\mathrm{H}_{2} \mathrm{O}_{2}$ in plant cells and presence of fungal hyphae (h) and conidia (c) were revealed by 3,3'-diaminobenzidine and trypan blue staining, respectively (Xiao et al. 2003). Note that hypersensitive response lesions (arrowheads) associated with $\mathrm{H}_{2} \mathrm{O}_{2}$ production (indicated by brownish color) were visible in leaves of the transgenic lines (right) but were absent from wild-type Col-gl (left). Bars represent $100 \mu \mathrm{M}$. B, Western blot analysis of protein extracts derived from leaves of a 4-week-old 35S::HA-RPW8.2 homozygous line. Samples were normalized for the amount of protein. Approximately equal amounts of total protein from soluble fraction and microsomal fractions were analyzed by immunoblotting. Correcting for total protein, $\approx 9 \%$ of the protein was in $\mathrm{S}$, whereas $\approx 22$ and $\approx 69 \%$ were associated with the 20,000 and $100,000 \times g$ pellet fractions. C, Western blot analysis of protein extracts derived from leaves of a transgenic line containing an empty vector $(\mathrm{V})$, the same 4-week-old 35S::HA-RPW8.2 homozygous line used in B (lane 1) and four homozygous lines of Np::HA-RPW8.2 (lanes 2-5) sprayed with $\mathrm{H}_{2} \mathrm{O}$ or $150 \mu \mathrm{M} \mathrm{SA}$. Total proteins were extracted from leaf tissues before or $48 \mathrm{~h}$ after treatment. Soluble fractions (s) and 16,000 $\times g$ pellets (p) were assayed. Approximately $50 \mu \mathrm{g}$ of total protein were loaded per lane and the HA:RPW8 fusion protein in the gel blot was detected with the monoclonal $\alpha$-haemagglutinin antibody (Roche). 
pathogen- or SA-responsive genes (Eulgem et al. 1999; Yu et al. 2001). These two constructs from the binary vector pBIN19Plus were introduced into Col-gl background. The powderymildew-susceptible accession Col-0 lacks $R P W 8.1$ and $R P W 8.2$ (Xiao et al. 2001) and, thus, is ideal for functional test of the $H A-R P W 8.2$ fusion gene. Twenty T1 Col-gl transgenic plants were generated for each construct and tested with powdery mildew isolate Erysiphe cichoracearum UCSC1. In all, 15 $35 S:: H A-R P W 8.2$ T1 plants and 13 Np::HA-RPW8.2 T1 plants were moderately resistant to the fungus, with disease reaction score (DR) 1 or 1-2. HR lesions were visible on the inoculated leaves of those resistant $\mathrm{T} 1$ and $\mathrm{T} 2$ plants 4 to 5 dpi (Fig. $3 \mathrm{~A}[\mathrm{a}]$ ). Diaminobenzidine (DAB) staining and subsequent trypan-blue staining (Xiao et al. 2003) were used to detect $\mathrm{H}_{2} \mathrm{O}_{2}$ accumulation induced by fungal penetration and to visualize the fungal structure. In inoculated Col-gl leaves, networks of fungal mycelia and conidiophores but no $\mathrm{H}_{2} \mathrm{O}_{2}$-producing whole epidermal cells were observed (Fig. 3A[b]). In contrast,

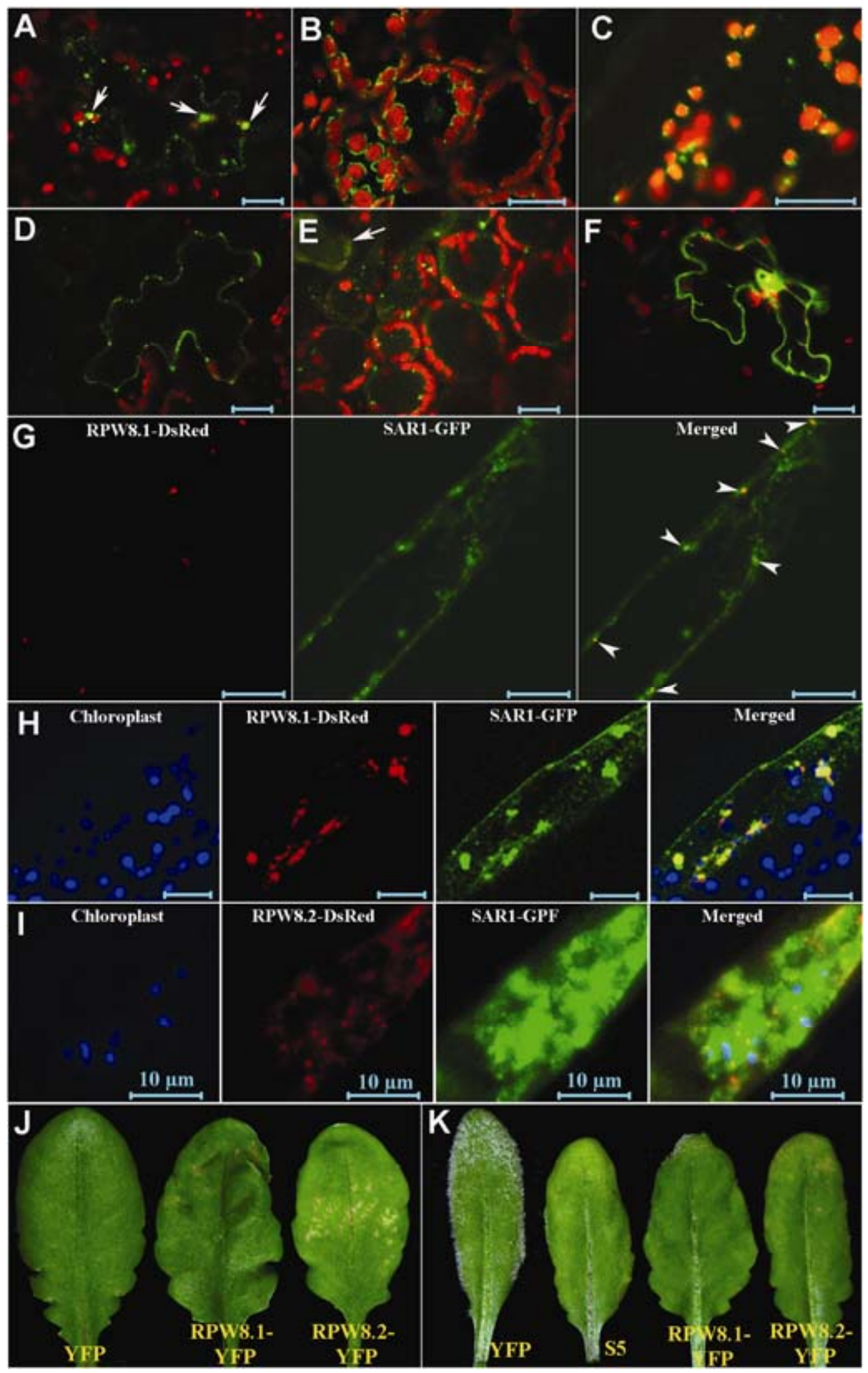


in the inoculated leaves of resistant plants transgenic for either $35 S:: H A-R P W 8.2$ (not shown) or Np::HA-RPW8.2, there was $\mathrm{H}_{2} \mathrm{O}_{2}$ production in epidermal cells penetrated by the fungus and there was only limited fungal growth with no or few conidiophores (Fig. 3A[b]). These results indicated that the HA: RPW8.2 fusion protein is functional.

\section{HA:RPW8.2 is enriched}

\section{in the membrane fraction and is induced by $\mathrm{SA}$.}

Results obtained from preliminary Western blot analysis using anti-HA antibody suggested that levels of HA:RPW8.2 in the soluble fraction from independent transgenic lines were very low. It is possible that either the RPW8.2 protein was underrepresented in the total protein extract prepared with our protein extraction protocol, presumably due to its likely membrane association, or that it has a rapid turnover. To test whether RPW8.2 was associated with the membrane fraction, the total protein was extracted as described by Devoto and associates (2002). The cell homogenate was fractionated by differential centrifugation to separate membrane vesicles by mass and size, adapting a protocol from Devoto and associates (1999). Fractions were tested for the presence of HA:RPW8.2 by immunoblotting with an anti-HA antibody. HA:RPW8.2 was detectable only as a weak signal in the soluble fraction. The intensity of the signal increased in the microsomal fractions and particularly in the $100,000 \times g$ high-speed pellet, at a mass of $\approx 22 \mathrm{kDa}$ (Fig. $3 B)$. These results suggest that the HA:RPW8.2 protein levels are higher in the membrane-enriched fraction.

In an earlier report, we showed that transcription of the $R P W 8$ genes under control of their native promoters involves a self-amplification mechanism via an SA-dependent feedback circuit (Xiao et al. 2003). However, it was not known whether enhanced transcription of the $R P W 8$ genes also led to enhanced level of the RPW8 proteins. To test this, independent transgenic lines homozygous for $H A-R P W 8.2$ driven by the native promoters or the $35 \mathrm{~S}$ promoter were sprayed with $150 \mu \mathrm{m}$ SA. After $48 \mathrm{~h}$, leaves were harvested and total protein extracts were prepared. The soluble fraction and $16,000 \times g$ pellet fraction were fractionated by sodium dodecyl sulfate polyacrylamide gel electrophoresis (SDS-PAGE) and assayed by Western blot with anti-HA antibody. A line containing the $35 S:: H A$ $R P W 8.2$ transgene had higher levels of HA:RPW8.2 than in four $N p:: H A-R P W 8.2$ lines (Fig. 3C). Significantly, there was no obvious increase in the HA:RPW8.2 level in the $35 S:: H A-$ $R P W 8.2$ line after SA treatment. In contrast, the levels of HA:RPW8.2 in the four Np::HA-RPW8.2 lines were lower before SA treatment and increased 3 to $10 \times$ in both the soluble and the membrane fractions after SA treatment. In addition, the intensity of the signal for HA:RPW8.2 was higher in the membrane-enriched fraction than in the soluble fraction in all five transgenic lines (Fig. 3C). These results indicated that SA indeed enhanced the accumulation of the HA:RPW8.2 protein.

\section{Expression and subcellular localization of fluorescence-tagged RPW8 proteins.}

To determine the subcellular localization of the two RPW8 proteins, we prepared C-terminal translational fusions of the $R P W 8.1$ and $R P W 8.2$ coding sequences with the yellow fluorescent protein (YFP) so as to leave the putative $\mathrm{N}$-terminus membrane localization signal intact. The sequence-confirmed chimeric genes RPW8.1-YFP and RPW8.2-YFP were cloned under control of the constitutive CaMV $35 S$ promoter. These two constructs were introduced into onion epidermal cells by particle bombardment. Both RPW8.1:YFP and RPW8.2:YFP appeared to be localized mainly in the endomembrane system possibly including the plasma membrane, the endoplasmic reticulum (ER), and the Golgi apparatus, because a significant proportion of the RPW8:YFP fluorescence was displayed as punctate bodies of various sizes along the plasma membrane as well as in the cytoplasm (Supplementary Figure 1). Some fluorescent spots seemed to move along with the streaming strands. This punctate localization pattern of RPW8:YFP was in contrast to the homogeneous distribution pattern of YFP alone. We then transiently expressed the fusion proteins in leaf epidermal cells of Arabidopsis Col-gl plants by bombardment and observed punctuate patterns of fluorescence similar to those found in onion epidermal cells. Interestingly, we noticed that RPW8.1:YFP but not RPW8.2:YFP formed several big fluorescent punctate bodies proximal to chloroplasts (Fig. 4A; data not shown).

To analyze the subcellular localization of the RPW8 proteins, we compared their transient expression with that of two GFP-fusion proteins, the small GTPase SAR1 and the receptor of the ER-retention signal H/KDEL (ERD2), which are localized to ER export sites and Golgi body, respectively (daSilva et al. 2004; Hanton and Brandizzi 2006), along with the expression of YFP alone in Arabidopsis leaf epidermal cells (Fig. 4F). The punctate localization patterns of RPW8.1:YFP and RPW8.2:YFP were similar to those of SAR1 and ERD2, suggesting that the localization sites of the RPW8 proteins may include Golgi-ER-associated endomembranes.

To study the expression and localization of the RPW8 proteins in a more native state, we stably expressed $R P W 8.1-Y F P$ and $R P W 8.2-Y F P$ under control of their native promoters (discussed below) and examined leaves from at least five plants of 10 independent T2 transgenic lines for each construct by confocal microscopy. RPW8.1:YFP was detected as a fluorescent

Fig. 4. Subcellular localization and functional tests of fluorescence-tagged RPW8. Green fluorescent protein (GFP)- and yellow fluorescent protein (YFP)tagged proteins were pseudocolored green, whereas DsRed were pseudocolored red and autofluorescent chloroplasts were pseudocolored A through F, red or $\mathbf{H}$ and $\mathbf{I}$, blue. The z-axis distance between images of a stack and the number of images projected into a single plane are shown in brackets. All bars except the ones indicated represent $20 \mu \mathrm{m}$. Representative images of merged GFP channel and red channel in A-F showed localization of YFP tagged proteins or YFP alone in relation to chloroplasts. Note that the chloroplasts were viewed only in the red channel and YFP-tagged proteins were viewed only in the GFP channel. A, One representative Arabidopsis epidermal cell (EC) transiently expressing $N p:: R P W 8.1-Y F P$. Arrows indicate bigger bright spots proximal to chloroplasts. B, Arabidopsis mesophyll cells (MC) $(0.68 \mu \mathrm{m}, 20$ images) stably expressing Np::RPW8.1-YFP. C, An Arabidopsis midvein EC from the abaxial side $(0.5 \mu \mathrm{m}, 20$ images) stably expressing $35 S: \because R P W 8.1-Y F P$. D, An Arabidopsis EC stably expressing Np::RPW8.2-YFP. E, Arabidopsis MCs $(0.64 \mu \mathrm{m}, 20$ images) stably expressing $N p:: R P W 8.2-Y F P$. Arrow indicates a dead cell. F, An Arabidopsis EC transiently expressing $35 S:: Y F P$. G and H, Sections of Arabidopsis midvein ECs from the abaxial side transiently coexpressing 35S::RPW8.1-DsRed and 35S::SAR1-GFP (G, single image; H, 1.4 4 , 10 images). Yellow-colored spots in G (indicated by arrowheads) and H reflect colocalization sites. I, Section of an Arabidopsis midvein EC from the abaxial side transiently coexpressing 35S::RPW8.2-DsRed and 35S::SAR1-GFP. J, Development of spontaneous hypersensitive response-like lesions (SHLs) in leaves of the indicated, representative transgenic lines. Arrows indicated SHLs. K, Disease reaction phenotypes of the indicated, representative transgenic lines at 8 days postinoculation of Erysiphe cichoracearum UCSC1. The expression of $Y F P$ alone was controlled by the $35 \mathrm{~S}$ promoter, and the expression of $R P W 8.1-Y F P$ or $R P W 8.2-Y F P$ was controlled by their native promoters in $\mathrm{J}$ and $\mathrm{K}$. Line S5 expressing both $R P W 8.1$ and $R P W 8.2$ by the native promoters was used as control in $\mathrm{K}$. 
ring-like structure surrounding or punctate spots proximal to chloroplasts in mesophyll cells (Fig. 4B) and punctate spots proximal to chloroplasts in epidermal cells in the midvein (Fig. 4C). RPW8.1:YFP was rarely detected in regular leaf epidermal cells. In contrast, RPW8.2:YFP was observed in both epidermal and mesophyll cells (Fig. 4D and E). Compared with RPW8.1:YFP, fluorescence from RPW8.2:YFP in mesophyll cells seemed less tightly associated with chloroplasts (Fig. $4 \mathrm{E})$. It is important to note that, in both the Np::RPW8.1-YFP and $N p:: R P W 8.2-Y F P$ transgenic lines, YFP fluorescence was detected in only some leaf epidermal or mesophyll cells that were often but not always found in the proximity of a developing lesion (Fig. 4E). Development of SHLs in some of these transgenic lines was mostly likely due to overexpression of the functional fusion proteins (discussed below). These observations suggested that expression of RPW8.1:YFP and RPW8.2:YFP from their native promoters in leaf tissues is heterogeneous and may be spatially different from each other.

To further determine whether the two RPW8 proteins localize to endomembranes associated with Golgi-ER, we tagged RPW8 with DsRed (Jach 2006) and transiently coexpressed $35 S:: R P W 8-D$ RRed with $35 S:: S A R 1-G F P$ or $35 S:: E R D 2-G F P$ (daSilva et al. 2004) in the midvein epidermal cells of Col-gl leaves by bombardment. SAR1:GFP was detected as diffused fluorescence in the cytoplasm with or without the presence of bright punctate spots and ring-like structures (Fig. 4G-I), as previously reported (daSilva et al. 2004). The punctate accumulation of SAR1:GFP likely represents an ER export site, most of which moves along the surface of ER together with the Golgi bodies (daSilva et al. 2004). In the cells coexpressing RPW8.1:DsRed and SAR1:GFP, we observed that the punctate spots of RPW8.1:DsRed mostly colocalized with SAR1:GFP (Fig. 4G). However, as expected, SAR1:GFP displayed a wider range of distribution and those punctate structures where RPW8.1:YFP was not observed may represent Golgi bodies. Consistent with this speculation, coexpression indicated that RPW8.1:DsRed and ERD2:GFP did not exhibit colocalization. Because RPW8.1 almost always localized proximal to chloroplasts, we collected signals from the red channel together with the GFP and DsRed channels to view the localization of RPW8.1:DsRed, SAR1:GFP, and chloroplasts. Indeed, RPW8.1:DsRed was found to accumulate around chloroplasts as various-sized fluorescent bodies where SAR1:GFP also accumulated, though the latter had a wider range of distribution (Fig. 4H). RPW8.2:DsRed also displayed overlapping localization with SAR1:GFP (Fig. 4I), but its association with chloroplasts was not as tight as RPW8.1:DsRed (Fig. 4E and I).

\section{RPW8.1:YFP and RPW8.2: YFP were functional.}

To assess functionality of the RPW8.1:YFP and RPW8.2:YFP fusion proteins, we generated and phenotypically examined Colgl transgenic lines expressing either one of these two fusion proteins under the control of their native promoters. We found that 17 of $118 N p:: R P W 8.1: Y F P$ T1 lines and 35 of $120 N p:$ : $R P W 8.2: Y F P \mathrm{~T} 1$ lines developed SHL after plants were grown in short-day conditions for 3 weeks, whereas all $35 S: \because Y F P$ expressing plants did not (Fig. 4J), suggesting that these two fusion proteins are functional. Next, we inoculated plants of those transgenic lines with $E$. cichoracearum UCSC1. We found that $\approx 32 \%$ of lines transgenic for Np::RPW8.1-YFP and $\approx 35 \%$ of lines transgenic for $N p:: R P W 8.2-Y F P$ were resistant (disease score $0-1)$ or moderately resistant (1 or 1-2) (Xiao et al. 2005) to the pathogen (Fig. 4K). Furthermore, we tested 10 of the above powdery-mildew-resistant lines from each category (either $R P W 8.1-Y F P$ or $R P W 8.2-Y F P$ ) with $H$. parasitica noco 2 under $\mathrm{RH}=85 \%$ conditions as described in Figure $1 \mathrm{~A}(\mathrm{~b}$ and $\mathrm{c})$ and found that these lines exhibited various degrees of enhanced resistance to noco2 (data not shown), providing further evidence that $R P W 8$ expression confers enhanced resistance to noco2. Combined, these results indicated that both RPW8.1:YFP and RPW8.2:YFP fusion proteins are functional in activating SHL and (enhanced) resistance to biotrophic pathogens. Therefore, the endomembrane localization of the two RPW8:YFP fusion proteins observed in this analysis reflects the localization of the native RPW8 proteins in Arabidopsis leaf tissues. In addition, this is consistent with the evidence from the localization of HA:RPW8.2 based on SDS-PAGE fractionation and Western analysis (Fig. 3).

\section{DISCUSSION}

One of the most interesting features of RPW8 is that it confers non-race specific resistance against powdery mildew (Xiao et al. 2001). Because RPW8 involves a self-amplification mechanism via the SA-feedback circuit for activation of HR and resistance (Xiao et al. 2003, 2005), we hypothesized that $R P W 8$ engages the basal resistance machinery to potentiate defenses against powdery mildew pathogens and predicted that, if other biotrophic pathogens can induce $R P W 8$ expression, $R P W 8$ may trigger effective resistance against them (Xiao et al. 2005). Data from the present analysis provided strong evidence for this model. We showed that $R P W 8$ transcriptional amplification by SA-feedback circuit may lead to accumulation of the RPW8 protein, because exogenous SA treatment increased the level of HA:RPW8.2 under control of the native promoter (Fig. 3C). More importantly, we found that $R P W 8$ expression from a single copy of $R P W 8$ under control of the native promoters (line S5) confers enhanced resistance to $H$. parasitica, a biotrophic oomycete pathogen different from powdery mildew (Fig. 1A and B). There was no detectable elevated SA level and $P R-1$ expression in soil-grown S5 plants compared with Col-gl plants (Xiao et al. 2003), suggesting that enhanced resistance to $H$. parasitica noco 2 is more likely due to $R P W 8$ expression induced by the pathogen (Fig. 1C). Most likely this enhanced resistance was underestimated because $R P W 8$-expression was attenuated under the conditions of $\approx 85 \% \mathrm{RH}$ (Xiao et al. 2003) in which the tests were conducted. Indeed, higher levels of $R P W 8$ expressions due to the presence of two or more copies of the $R P W 8$ transgenes correlated with higher levels of enhanced resistance to noco2 (Fig. 1A through C). Conversely, greater attenuation of $R P W 8$ expression by $\mathrm{RH}=100 \%$ correlated with increased susceptibility of S5 and S6 to noco2 (Fig. 1A through C). This is consistent with our previous observation that high-humidity conditions could compromise $R P W 8$-mediated powdery mildew resistance in the same transgenic line S5 used in this analysis (Xiao et al. 2003), suggesting that the enhanced resistance of S5 to noco2 most likely shares the same mechanism with that of powdery mildew resistance. These results collectively suggest that $R P W 8$ may be better defined as a signaling component that strengthens the SA-dependent signaling for basal resistance against biotrophic pathogens than as a powdery-mildew-specific $R$ gene. When its expression is induced to a certain level, $R P W 8$ may initiate the SA-dependent feedback amplification circuit, resulting in sensitization for pathogen-induced HR cell death and thereby activating local resistance against biotrophic pathogens such as powdery mildews and oomycete $H$. parasitica in a nonrace-specific manner. Higher $R P W 8$ expression also may lead to activation of SAR as indicated by higher levels of constitutive $P R 1$ expression in transgenic lines containing multiple copies of $R P W 8$ (Xiao et al. 2003, 2005; this analysis) and this also may contribute to enhanced resistance to $H$. parasitica in $R P W 8$ overexpressing plants. A similar mechanism has been proposed for a newly cloned $R$ gene, $R F O 1$, which confers broad-spectrum resistance to Fusarium races (Diener and Ausubel 2005). 
RFO1 is identical to the previously named Arabidopsis gene WAKL22, which encodes a receptor-like kinase that does not contain an extracellular LRR domain (Diener and Ausubel 2005). Like $R P W 8, R F O 1$ also is induced by the pathogen and has been envisaged as a signaling component of a defense pathway (Diener and Ausubel 2005). Additional indirect evidence for $R P W 8$ as a signaling component is provided by the finding that $R P W 8$ is induced by ssi4, a gain-of-function mutation in a TIR-NBS-LRR gene that results in constitutive activation of defense responses (Zhou et al. 2004). Interestingly, ssi4-activated defenses also can be attenuated by high humidity (Shirano et al. 2002; Zhou et al. 2004). Testing RPW8-expressing plants with other types of biotrophic pathogens under normal RH (50 to $80 \%$ ) conditions should help consolidate the conclusion that $R P W 8$ is better defined as a signaling gene that stimulates basal resistance. However, given that Arabidopsis accessions (such as Col-0) lacking $R P W 8$ can mount $R$-mediated resistance and basal resistance to different pathogens other than powdery mildew, $R P W 8$ is unlikely to be an indispensable component of plant basal resistance.

Plants of the $R P W 8$-overexpressing line $\mathrm{S} 24$ also exhibited enhanced resistance to a viral pathogen, CaMV (Fig. 2A). Again, this is not unexpected; because the virus may strictly require live host cells for multiplication, SHL caused by $R P W 8$ overexpression may hinder spreading of the virus. Broad-spectrum resistance also has been observed in plants overexpressing other $R$ genes (Oldroyd and Staskawicz 1998; Tang et al. 1999 ) or an $R$-signaling component (Cao et al. 1998; Chern et al. 2005). Interestingly, our data showed that $R P W 8$ overexpression did not have a significant effect on disease symptoms and growth of a virulent $P$. syringae strain. This suggests that basal resistance strengthened by $R P W 8$ overexpression is effective only in restricting biotrophic pathogens and that an additional or separate signal input is required for activation of basal resistance against hemibiotrophic bacterial pathogens. Similar phenotypes were reported for the edrl mutant, in which loss-of-function mutation in a $M A P K K K$ gene confers enhanced resistance to powdery mildew but not to $P$. syringae (Frye and Innes 1998; Frye et al. 2001). In a recent report, we showed that EDRI appears to be a negative regulator of $R P W 8$ signaling (Xiao et al. 2005), which is consistent with a role of $R P W 8$ in stimulation of basal defenses specifically against biotrophic fungal pathogens. Also, we recently observed that the lesion-mimic mutant acd5 with enhanced disease susceptibility to $P$. syringae pv. maculicola (Greenberg et al. 2000) displayed enhanced resistance to E. cichoracearum UCSC1 (S. Xiao, unpublished data), further supporting the notion that basal defense against strictly biotrophic pathogens may differ from that against hemibiotrophic bacterial pathogens such as P. syringae.

On the other hand, necrotrophic pathogens have a different mode of parasitism. Unlike biotrophic pathogens, they may not be restricted by host cell death. In fact, it was reported that HR induced by an avirulent $P$. syringae strain appeared to facilitate infection by B. cinerea (Govrin and Levine 2000). A plethora of evidence has now suggested that plant resistance to necrotrophic pathogens requires JA and ET signaling, which may actually be antagonistic to the SA-signaling pathway (Feys and Parker 2000; Glazebrook 2005; Gupta et al. 2000; Ton et al. 2002). Our observation that $R P W 8$-overexpressing plants were more susceptible to necrotrophic fungal pathogens $A$. brassicicola and $B$. cinerea reinforces this notion. Weakened basal resistance against the two necrotrophs in the $R P W 8$-overexpressing plants could be due to repression of the JA-ET signaling by hyperactivation of the SA signaling or possible facilitation of fungal growth by concurrent development of SHL. A detailed analysis of the interaction between SA signaling and JA-ET signaling will be done to confirm this inference. Thus, although there is great potential in utilization of broad-spectrum $R$ genes such as $R P W 8$ and $R F O 1$ or signaling components of the conserved defense pathways in controlling biotrophic pathogens, caution is required to avoid causing severe imbalance of different defense mechanisms when designing strategies for engineering plant disease resistance using specific $R$ genes or $R$ gene-signaling pathway components.

Determination of the subcellular localization of the RPW8 proteins in the plant cell is the first step toward understanding how these proteins function in defense. The RPW8.1 (GenBank accession number AAK09266) and RPW8.2 (AAK09267) proteins are predicted to encode an $\mathrm{N}$-terminal transmembrane domain or a signal peptide (by TMpred or TMHMM 2.0 and SignalP 3.0, respectively). By using a free web-based program, "Prediction of Protein Localization Sites" (PSORT), both RPW8.1 and RPW8.2 were predicted to be localized to ER membrane with a medium to a high probability $(0.55$ for RPW8.1 and 0.82 for RPW8.2) and to plasma membrane (RPW8.2) and Golgi body (RPW8.1) with a low probability (0.19 and 0.10 , respectively). Our results, showing that HA:RPW8.2 was enriched in the membrane fraction (Fig. 3B and C) and RPW8.1:YFP and RPW8.2:YFP appeared to be localized to the endomembrane system, overlapping with the ER marker protein, the small GTPase SAR1 (Fig. 4G through I), generally agreed with the predictions by PSORT. Interestingly, we observed that, when expressed under the native promoters, RPW8.1:YFP was predominantly expressed in mesophyll cells whereas RPW8.2:YFP was expressed in both epidermal cells and mesophyll cells. This suggests that subtle differences in tissue-specific expression may exist between these two genes or proteins and there may be a synergistic or complementary effect in resistance when these two proteins are expressed together. This, in turn, may provide a likely explanation for evolution and maintenance of both $R P W 8.1$ and $R P W 8.2$ in a number of natural Arabidopsis accessions, including Ms-0, from which the two $R P W 8$ genes were isolated (Xiao et al. 2001). Considering that $R P W 8.1$ and $R P W 8.2$ were induced by powdery mildew (Xiao et al. 2005) and $H$. parasitica (this analysis), a relevant future question to be asked is whether and how the two RPW8 proteins in the leaf epidermal and mesophyll cells change their expression levels or localization in response to pathogen penetration.

\section{MATERIALS AND METHODS}

\section{Plant materials and cultivation.}

Col-gl and T8 generation plants of three homozygous transgenic lines, S5, S6, and S24, containing a single copy, two copies, and at least four copies, respectively, of RPW8.1 and RPW8.2 under control of their native promoters (Xiao et al. 2003) were used for this analysis. Unless otherwise indicated, plants were grown on MS-agar medium under short-day conditions ( $8 \mathrm{~h}$ of light and $16 \mathrm{~h}$ of dark) for 2 to 5 weeks and subsequently transferred to perlite wetted with half-strength MS salt liquid in Magenta Vessels (77 by $77 \mathrm{~mm}$, Sigma, St. Louis) and kept in long-day conditions (16 h of light and $8 \mathrm{~h}$ of dark) (Xiao et al. 2003). Light intensity was adjusted to $\approx 120 \mu \mathrm{mol} \mathrm{m} \mathrm{m}^{-2} \mathrm{~s}^{-2}$ in all the growth chambers. RH was controlled by covering the plants with plastic domes with or without holes, or magenta box lids with or without a $0.22-\mu \mathrm{m}$ membrane vent.

\section{Pathogen strains and inoculation.}

Methods of inoculation for isolate E. cichoracearum UCSC1 were the same as reported (Xiao et al. 1997). Inoculation of $H$. parasitica noco 2 isolate on 3 - to 4 -week-old plants 
and quantification of disease susceptibility were conducted according to McDowell and associates (2000). For viral infection, Brassica napus leaves infected with CaMV (strain Cabb B-JI) were ground with $0.1 \mathrm{M} \mathrm{Na}_{2} \mathrm{PO}_{4}$ buffer and the supernatant then was filter $(0.22 \mu \mathrm{m})$ sterilized. Inoculation was performed according to Cecchini and associates (1997). For bacterial infection, fully expanded leaves were infiltrated with a suspension of P. syringae pv. maculicola $\mathrm{ES} 4326\left(\approx 10^{4} \mathrm{CFU} / \mathrm{ml}\right)$ in $10 \mathrm{mM}$ $\mathrm{MgCl}_{2}$. Leaf discs were sampled immediately after infiltration or at 4 dpi with a cork borer, ground in $10 \mathrm{mM} \mathrm{MgCl}_{2}$, serially diluted, and plated on King's B agar plates. For infection with the necrotrophic pathogens A. brassicicola MUCL 20297 and Botrytis cinerea IMI 169558, leaves were punctured with a fine needle and applied with $2 \mu \mathrm{l}$ of spore suspension (equivalent to $10^{8}$ spores/ $\mu \mathrm{l}$ ) or $\mathrm{H}_{2} \mathrm{O}$ at the wound sites.

\section{Generation of $H A-R P W 8.2$ transgenic lines.}

Coding sequences of RPW8.2 (amplified by HAMC3F: 5'CGGGATCCAATGATTGCTGAGGTTGCCGCA-3' and EcoR82R: 5'-CGGAATTCTCAAGAATCATCACTGCAGAA CGT-3') were in-frame cloned into BamHI and EcoRI sites of plasmid pPILY which contains an intron-tagged $H A$ epitope for translational fusion with HA at the N-terminus of RPW8.2 (Ferrando et al. 2000). The recombinant plasmids, upon confirmation by sequencing, were digested with $K p n I$ to release the $2 \times 35 S:: H A-R P W 8.2$ cassettes which subsequently were cloned to the KpnI site of the binary vector pBIN19-plus. For expression of $H A-R P W 8.2$ from its native promoter, a $1.0-\mathrm{kb} 5^{\prime}$ sequence upstream of ATG start codon of $R P W 8.2$ was amplified by $5^{\prime}$-CCCTAAGCTTACTCTCCAAGCACT-3' and 5'-GCTC TAGATTTCTTGAAATTAGTTTGTTAGCTC- $3^{\prime}$ and used to replace the $2 \times 35 \mathrm{~S}$ promoter sequence in the $2 \times 35 \mathrm{~S}:: \mathrm{HA}$ $R P W 8.2 / \mathrm{pPILY}$ plasmid using the $\mathrm{XhoI}$ and HindIII sites. The cassette then was released by $K p n I$ digestion and cloned into the KpnI site of pBIN19-plus. The recombinant pBIN19-plus plasmids were introduced into Agrobacterium GV3101 and used for transformation of Col-gl plants.

\section{Transient and stable expression of fluorescence-tagged RPW8 proteins.}

To make an YFP-tagged RPW8 gene, RPW8.1 and RPW8.2 $3^{\prime}$ flanking sequences were amplified by BamR813'F (5'-GAG GATCCAGAGCTTGATAAAAAAAAACAGAG-3') and BglR 813'R (5'-ACATAGATCTCAAAAGAAGCGAA-3') and BamR 823'F (5'-ATGGATCCTGATGTCCTAATTGTGTCAAAC-3') and BglR823'R (5'-TGAGATCTTTTGTTGTTTTTTACTCT$3^{\prime}$ ), respectively, cut by $B a m \mathrm{HI}$ and $B g l \mathrm{II}$, and cloned into the BamHI site of binary vector pPZP211 (Hajdukiewicz et al. 1994), resulting in plasmids pPZPR813' and pPZPR823', respectively. The YFP coding region was amplified from $\mathrm{pEYFP}-$ C1 (Clontech, Palo Alto, CA, U.S.A.) with primers 5'-TCGGA TCCATGGTGAGCAAGGGCGAG-3' and 5'-GCAGATCTCA CTTGTACAGCTCGTCCATG-3', digested with BamHI and $B g l I I$, and cloned into the BamHI site of pPZPR813', pPZPR823', and binary vector pCB302-3 (Xiang et al. 1999), resulting in plasmids pPZPYFP13', pPZPYFP23', and pBam EYFP. For constitutive expression of RPW8-EYFP fusion protein, the RPW8.1 coding sequence (amplified with primers HAMC2F 5'-CGGGATCCAATGCCGATTGGTGAGCTTGC GATA-3' and BamR81R 5'-GCGGATCCAGCTCTTATTTTA CTACAAGCAGA-3') and RPW8.2 coding sequence (amplified with primers HAMC3F and BamR82R 5'-CGCGGATCCAGA ATCATCACTGCAGAACGTAAA-3') were in-frame cloned into the BamHI site of pBamEYFP, resulting in plasmids pR81EYFP and pR82EYFP, respectively. For tests of RPW8 colocalization with SAR1:GFP and ERD2:GFP, YFP coding sequences in $\mathrm{pR} 81 \mathrm{EYFP}$ and $\mathrm{pR} 82 \mathrm{EYFP}$ were replaced by
DsRed coding sequences amplified from pDsRed-Express (Clontech) with primers DsRedF (5'-TAGGATCCATGGCCT CCTCCGAGG-3') and DsRedR (5'-AAAGATCTCCGCTACA GGAACAGGTGGTG-3'), resulting in plasmids pR81DsRed and pR82DsRed. The plasmid DNAs of pR81EYFP and pR82EYFP were introduced into onion epidermal cells or Colgl leaves, and plasmid DNAs of pR81DsRed or pR82DsRed were introduced into Col-gl leaves together with plasmid DNA containing 35S::SAR1-GFP or 35S::ERD2-GFP by using a Biolistic PDS-1000/He system (BioRad, Hercules, CA, U.S.A.) following the manufacturer's instruction. Tungsten particles (M20) were coated with the respective plasmid DNA and a helium pressure of $7.5 \mathrm{MPa}(1,100$-psi rupture) was employed. The target distance between the stop screen and onion piece or Col$\mathrm{gl}$ leaves was set at $6 \mathrm{~cm}$. After bombardment, onion pieces or Col-gl leaves were kept in darkness at room temperature for 15 to $24 \mathrm{~h}$ before examination under a confocal microscope. For native expression of the RPW8:YFP fusion proteins, the promoter and coding sequences of RPW8.1 and RPW8.2 were amplified with BamR81PF (5'-TCGGATCCATTGGTCTCTCA ATTTGTTTATTT-3') and BamR81R, BamR82PF (5'-TTGGAT CCTCACCGAAATTGTTAGTATTCACG-3') and BamR82R, cut by BamHI, and cloned into the BamHI sites of pPZPYFP13' and pPZPYFP23', generating plasmids pPR81EYFP and pPR82EYFP, respectively. Then, pPR81EYFP and pPR82EYFP were introduced into Col-0 and Col-gl by Agrobacterium-mediated transformation. All T1 transformants were examined for development of SHL, disease resistance to powdery mildew isolate E. cichoracearum UCSC1. Transient or stable expression of YFP or RPW8-YFP fusion proteins in T2 transgenic plants were examined and imaged using a Zeiss LSM 510 laser scanning confocal microscope with $\times 10$ NA 0.8 dry and $\times 63$ NA 1.2 water-immersion lenses (Carl Zeiss Inc., Thornwood, NY, U.S.A.). Single optical sections or a stack of $\mathrm{z}$ sections were obtained by adjusting pinhole, detector gain, and laser transmission according to the user's manual of Zeiss LSM510 to produce the best signal/noise ratio. GFP or YFP fluorescence was acquired with an Argon 488-nm laser exciter and a band pass emission filter BP 505-550 (GFP channel). Auto fluorescence of the chloroplast was acquired with the same exciter and a long-pass emission filter LP 650 (red channel). For colocalization experiment of RPW8:DsRed with SAR1:GFP or ERD2:GFP, multi-tracks were configured with the GFP channel setting as above plus a DsRed channel with an HeNe1 543$\mathrm{nm}$ laser exciter and a band pass emission filter BP 560-615. The image data were processed using Adobe Photoshop (Mountain View, CA, U.S.A.).

\section{Protein extraction, membrane vesicle fractionation, and Western blot analysis.}

The total protein was extracted as described by Devoto and associates (2002). For differential centrifugation experiments, we used a protocol adapted from Devoto and associates (1999). The cell homogenate was centrifuged at 3,000 $\times g$ for $5 \mathrm{~min}$ at $4^{\circ} \mathrm{C}$. The supernatant was recovered and further centrifuged at 10,000 and $20,000 \times g$ for $20 \mathrm{~min}$ and then at $100,000 \times g$ for $45 \mathrm{~min}$, with the supernatant from each spin taken for use in the next centrifugation step. The resulting pellets following each centrifugation step were resuspended in cold lysis buffer. Proteins were quantified according to the method of Bradford using bovine serum albumin as a standard. Protein extracts were incubated in SDS denaturing buffer $(200$ $\mathrm{mM}$ Tris- $\mathrm{HCl}, 20 \%$ [wt/vol] glycerol, $5 \mathrm{mM}$ EDTA, $0.02 \%$ [wt/vol] bromophenol blue, and $2 \%$ [wt/vol] SDS) for $5 \mathrm{~min}$ at $70^{\circ} \mathrm{C}$, separated by $15 \%$ SDS-PAGE, and transferred to polyvinylidene diflouride membranes (Roche, Branchburg, NJ, U.S.A.). To detect HA:RPW8, we used anti-HA antibody 
(Roche). Blots were developed using the SuperSignal West Femto maximum sensitivity substrate (Pierce, Rockford, IL, U.S.A.).

\section{Other analyses.}

Methods for quantification of relative mRNA levels of $R P W 8.1$ and PRI by Applied Biosystems 7300 Real-Time PCR System were the same as previously described (Xiao et al. 2003). Histochemical detection of $\mathrm{H}_{2} \mathrm{O}_{2}$ with 3,3'-diaminobenzidine and host cell death and fungal structure by trypan blue also were according to Xiao and associates (2003).

\section{ACKNOWLEDGMENTS}

This project was supported by a startup fund from the Center for Biosystems Research, University of Maryland Biotechnology Institute, and by a grant from the National Research Initiative of the United States Department of Agriculture Cooperative State Research, Education and Extension Service (grant number 2005-35319-15656) to S. Xiao. We thank J. McDowell (Virginia Tech) for H. parasitica noco2; X. Dong (Duke University) for P. syringae pv. maculicola ES4326 and Alternaria brassicicola MUCL 20297; S. Somerville (Carnegie Institution) for E. cichoracearum UCSC1; N. S. Al-Kaff (John Innes Center, U.K.) for CaMV Cabb B-JI; B P. H. J. Thomma and W. F. Broekaert for providing B. cinerea IMI 169558; J. Culver for constructs of ERD2 and SAR1 markers; and E. Patrick, P. Lunness, and S. Tangchaiburana for technical support. We also thank two anonymous reviewers for comments on the earlier version of this manuscript.

\section{LITERATURE CITED}

Aarts, N., Metz, M., Holub, E., Staskawicz, B. J., Daniels, M. J., and Parker, J. E. 1998. Different requirements for EDS1 and NDR1 by disease resistance genes define at least two $R$ gene-mediated signaling pathways in Arabidopsis. Proc. Natl. Acad. Sci. U.S.A. 95:1030610311.

Belkhadir, Y., Subramaniam, R., and Dangl, J. L. 2004. Plant disease resistance protein signaling: NBS-LRR proteins and their partners. Curr. Opin. Plant Biol. 7:391-399.

Braun, U. 1987. A Monograph of the Erysiphales (Powdery Mildews). J. Cramer, Berlin.

Cao, H., Li, X., and Dong, X. 1998. Generation of broad-spectrum disease resistance by overexpression of an essential regulatory gene in systemic acquired resistance. Proc. Natl. Acad. Sci. U.S.A. 95:6531-6536.

Cecchini, E., Gong, Z., Geri, C., Covey, S. N., and Milner, J. J. 1997. Transgenic Arabidopsis lines expressing gene VI from Cauliflower mosaic virus variants exhibit a range of symptom-like phenotypes and accumulate inclusion bodies. Mol. Plant-Microbe Interact. 10:10941101.

Cecchini, E., Al-Kaff, N. S., Bannister, A., Giannakou, M. E., McCallum, D. G., Maule, A. J., Milner, J. J., and Covey, S. N. 1998. Pathogenic interactions between variants of Cauliflower mosaic virus and Arabidopsis thaliana. J. Exp. Bot. 49:731-737.

Chern, M., Fitzgerald, H. A., Canlas, P. E., Navarre, D. A., and Ronald, P. C. 2005. Overexpression of a rice NPR1 homolog leads to constitutive activation of defense response and hypersensitivity to light. Mol. PlantMicrobe Interact. 18:511-520.

Dangl, J. L., and Jones, J. D. G. 2001. Plant pathogens and integrated defence responses to infection. Nature 411:826-833.

daSilva, L. L., Snapp, E. L., Denecke, J., Lippincott-Schwartz, J., Hawes, C., and Brandizzi, F. 2004. Endoplasmic reticulum export sites and Golgi bodies behave as single mobile secretory units in plant cells. Plant Cell 16:1753-1771.

Devoto, A., Piffanelli, P., Nilsson, I., Wallin, E., Panstruga, R., von Heijne, G., and Schulze-Lefert, P. 1999. Topology, subcellular localization, and sequence diversity of the Mlo family in plants. J. Biol. Chem. 274:34993-35004.

Devoto, A. Nieto-Rostro, M., Xie, D., Ellis, C., Harmston, R., Patrick, E., Davis, J., Sherratt, L., Coleman, M., and Turner, J. G. 2002. COI1 links jasmonate signalling and fertility to the SCF ubiquitin-ligase complex in Arabidopsis. Plant J. 32:457-466.

Diener, A. C., and Ausubel, F. M. 2005. RESISTANCE TO FUSARIUM OXYSPORUM 1, a dominant Arabidopsis disease-resistance gene, is not race specific. Genetics 171:305-321.

Durrant, W. E., and Dong, X. 2004. Systemic acquired resistance. Annu. Rev. Phytopathol. 42:185-209.
Eulgem, T., Rushton, P. J., Schmelzer, E., Hahlbrock, K., and Somssich, I. E. 1999. Early nuclear events in plant defence signalling: Rapid gene activation by WRKY transcription factors. EMBO (Eur. Mol. Biol. Organ.) J. 18:4689-4699.

Ferrando, A., Farras, R., Jasik, J., Schell, J., and Koncz, C. 2000. Introntagged epitope: A tool for facile detection and purification of proteins expressed in Agrobacterium-transformed plant cells. Plant J. 22:553-560.

Feys, B. J., and Parker, J. E. 2000. Interplay of signaling pathways in plant disease resistance. Trends Genet. 16:449-455.

Frye, C. A., and Innes, R. W. 1998. An Arabidopsis mutant with enhanced resistance to powdery mildew. Plant Cell 10:947-956.

Frye, C. A., Tang, D., and Innes, R. W. 2001. Negative regulation of defense responses in plants by a conserved MAPKK kinase. Proc. Natl. Acad. Sci. U.S.A. 98:373-378.

Glazebrook, J. 2001. Genes controlling expression of defense responses in Arabidopsis-2001 status. Curr. Opin. Plant Biol. 4:301-308.

Glazebrook, J. 2005. Contrasting mechanisms of defense against biotrophic and necrotrophic pathogens. Annu. Rev. Phytopathol. 43:205-227.

Govrin, E. M., and Levine, A. 2000. The hypersensitive response facilitates plant infection by the necrotrophic pathogen Botrytis cinerea. Curr. Biol. 10:751-757.

Greenberg, J. T., Silverman, F. P., and Liang, H. 2000. Uncoupling salicylic acid-dependent cell death and defense-related responses from disease resistance in the Arabidopsis mutant acd5. Genetics 156:341-350.

Gupta, V., Willits, M. G., and Glazebrook, J. 2000. Arabidopsis thaliana EDS4 contributes to salicylic acid (SA)-dependent expression of defense responses: Evidence for inhibition of jasmonic acid signaling by SA. Mol. Plant-Microbe Interact. 13:503-511.

Hajdukiewicz, P., Svab, Z., and Maliga, P. 1994. The small, versatile pPZP family of Agrobacterium binary vectors for plant transformation. Plant Mol. Biol. 25:989-994.

Hammond-Kosack, K. E., and Jones, J. D. G., 1997. Plant disease resistance genes. Annu. Rev. Plant Physiol. Plant Mol. Biol. 48:575-607.

Hanton, S. L., and Brandizzi, F. 2006. Fluorescent proteins as markers in the plant secretory pathway. Microsc. Res. Technol. 69:152-159.

Heath, M. C. 2000. Hypersensitive response-related death. Plant Mol. Biol. 44:321-334.

Jach, G. 2006. Use of fluorescent proteins as reporters. Methods Mol. Biol. 323:275-291.

McDowell, J. M., Cuzick, A., Can, C., Beynon, J., Dangl, J. L., and Holub, E. B. 2000. Downy mildew (Peronospora parasitica) resistance genes in Arabidopsis vary in functional requirements for NDR1, EDS1, NPR1 and salicylic acid accumulation. Plant J. 22:523-529.

Mur, L. A., Kenton, P., Atzorn, R., Miersch, O., and Wasternack, C. 2006. The outcomes of concentration-specific interactions between salicylate and jasmonate signaling include synergy, antagonism, and oxidative stress leading to cell death. Plant Physiol. 140:249-262.

Oldroyd, G. E. D., and Staskawicz, B. J. 1998. Genetically engineered broad-spectrum disease resistance in tomato. Proc. Natl. Acad. Sci. U.S.A. 95:10300-10305.

Parker, J. E. Coleman, M. J., Szabò, V., Frost, L. N., Schmidt, R., van der Biezen, E. A., Moores, T., Dean, C., Daniels, M. J., and Jones, J. D. G. 1997. The Arabidopsis downy mildew resistance gene RPP5 shares similarity to the toll and interleukin-1 receptors with $N$ and L6. Plant Cell 9:879-894.

Shirano, Y., Kachroo, P., Shah, J., and Klessig, D. F. 2002. A gain-of-function mutation in an Arabidopsis toll interleukin1 receptor-nucleotide binding site leucine-rich repeat type $R$ gene triggers defense responses and results in enhanced disease resistance. Plant Cell 14:3149-3162.

Staskawicz, B. J., Ausubel, F. M., Baker, B. J., Ellis, J. G., and Jones, J. D. G. 1995. Molecular genetics of plant disease resistance. Science 268:661-667.

Tang, X., Xie, M., Kim, Y. J., Zhou, J., Klessig, D. F., and Martin, G. B. 1999. Overexpression of Pto activates defense responses and confers broad resistance. Plant Cell 11:15-29.

Ton, J., Van Pelt, J. A., Van Loon, L. C., and Pieterse, C. M. 2002. Differential effectiveness of salicylate-dependent and jasmonate/ethylene-dependent induced resistance in Arabidopsis. Mol. Plant-Microbe Interact. $15: 27-34$

van der Biezen, E. A., Freddie, C. T., Kahn, K., Parker, J. E., and Jones, J. D. 2002. Arabidopsis RPP4 is a member of the RPP5 multigene family of $T I R-N B-L R R$ genes and confers downy mildew resistance through multiple signalling components. Plant J. 29:439-451.

Whipps, J. M., Budge, S.P., and Fenlon, J. S. 1998. Characteristics and host range of tomato powdery mildew. Plant Pathol. 47:36-48.

Wiermer, M., Feys, B. J., and Parker, J. E. 2005. Plant immunity: The EDS1 regulatory node. Curr. Opin. Plant Biol. 8:383-389.

Xiang, C., Han, P., Lutziger, I., Wang, K., and Oliver, D. J. 1999. A mini binary vector series for plant transformation. Plant Mol. Biol. 40:711-717.

Xiao, S., Ellwood, S., Findlay, K., Oliver, R. P., and Turner, J. G. 1997. 
Characterization of three loci controlling resistance of Arabidopsis thaliana accession Ms-0 to two powdery mildew diseases. Plant J. 12:757-768.

Xiao, S., Brown, S., Patrick, E., Brearley, C., and Turner, J. G. 2003. Enhanced transcription of the Arabidopsis disease resistance genes $R P W 8.1$ and $R P W 8.2$ via a salicylic acid-dependent amplification circuit is required for hypersensitive cell death. Plant Cell 15:33-45.

Xiao, S., Calis, O., Patrick, E., Zhang, G., Charoenwattana, P., Muskett, P., Parker, J. E., and Turner, J. G. 2005. The atypical resistance gene, $R P W 8$, recruits components of basal defence for powdery mildew resistance in Arabidopsis. Plant J. 42:95-110.

Xiao, S. Y., Ellwood, S., Calis, O., Patrick, E., Li, T. X., Coleman, M., and Turner, J. G. 2001. Broad-spectrum mildew resistance in Arabidopsis thaliana mediated by RPW8. Science 291:118-120.

Yu, D., Chen, C., and Chen, Z. 2001. Evidence for an important role of WRKY DNA binding proteins in the regulation of NPRl gene expression. Plant Cell 13:1527-1540.

Zhou, F., Menke, F. L., Yoshioka, K., Moder, W., Shirano, Y., and Klessig, D. F. 2004. High humidity suppresses ssi4-mediated cell death and disease resistance upstream of MAP kinase activation, $\mathrm{H}_{2} \mathrm{O}_{2}$ production and defense gene expression. Plant J. 39:920-932.

\section{AUTHOR-RECOMMENDED INTERNET RESOURCE}

PSORT website: psort.nibb.ac.jp/form.html 